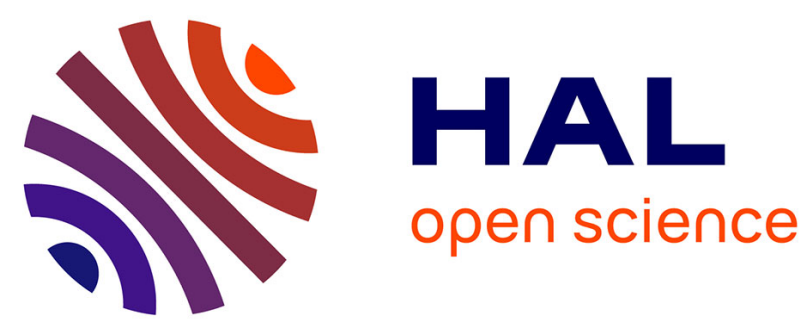

\title{
SPECTROSCOPIC PROPERTIES OF Ca-SUBSTITUTED GADOLINIUM GALLIUM GARNET DOPED WITH V4+
}

A. Suchocki, A. Brenier, C. Pedrini, G. Boulon

\section{- To cite this version:}

A. Suchocki, A. Brenier, C. Pedrini, G. Boulon. SPECTROSCOPIC PROPERTIES OF CaSUBSTITUTED GADOLINIUM GALLIUM GARNET DOPED WITH V4+. Journal de Physique IV Proceedings, 1991, 01 (C7), pp.C7-323-C7-326. 10.1051/jp4:1991786 . jpa-00251029

HAL Id: jpa-00251029

https://hal.science/jpa-00251029

Submitted on 1 Jan 1991

HAL is a multi-disciplinary open access archive for the deposit and dissemination of scientific research documents, whether they are published or not. The documents may come from teaching and research institutions in France or abroad, or from public or private research centers.
L'archive ouverte pluridisciplinaire HAL, est destinée au dépôt et à la diffusion de documents scientifiques de niveau recherche, publiés ou non, émanant des établissements d'enseignement et de recherche français ou étrangers, des laboratoires publics ou privés. 


\title{
SPECTROSCOPIC PROPERTIES OF Ca-SURSTITUTED GADOLINIUM GALLIUM GARNET DOPED WITH V4+
}

\author{
A. SUCHOCKI ${ }^{*, * *}$, A. BRENIER*, C. PEDRINI ${ }^{*}$ and G. BOULON* \\ *URA 442 CNRS, University Lyon, 43 boulevard du 11 novembre 1918, F-69622 Villeurbanne cedex, \\ France \\ **Institute of Physics, Polish Academy of Sciences, AL Lotnikow 32/46, PL-02-668 Warszawa, Poland
}

\begin{abstract}
The results of absorption, luminescence and luminescence excitation, fluorescence decay kinetics and photoconductivity measurements of $\mathrm{Gd}_{3} \mathrm{Ga}_{5} \mathrm{O}_{12}: \mathrm{V}^{4+}, \mathrm{Ca}^{2+}(0.5 \% \mathrm{~mol}$.) garnet are reported in detall. A strong quenching of the luminescence of $\mathrm{V}^{4+}$ ions in octahedral sites by the energy transfer to $V^{4+}$ ions in tetrahedral sites is observed. Broad, strong bands observed in absorption and luminescence excitation spectra of octahedral $\mathrm{V}^{4+}$ ions in the ultraviolet region are assigned to small polarons bound at the $\mathrm{V}^{4+}$ ions in octahedral sites.
\end{abstract}

\section{Introduction}

The $\mathrm{V}^{4+}$ dopant in various hosts is considered to be a very promising system for tunable laser application, either as an active lasing center or a luminescence coactivator of rare earth ions. Recently, we published the resuits of crystal growth and the first studies of optical properties of the $\mathrm{Gd}_{3} \mathrm{Ga}_{5} \mathrm{O}_{12}: \mathrm{V}^{4+}, \mathrm{Ca}^{2+}(0.5 \% \mathrm{~mol}$ ) garnet crystal (1). It has been shown there that vanadium lons occupy octahedral and tetrahedral sites in the garnet host. The purpose of this paper is to report in more detail on the spectroscopic and electrical properties of such crystals.

\section{Samples and experimental techniques.}

The crystal has been grown by the Czochralski method under a nitrogen gas flow. Vanadium was added in the form of $\mathrm{V}_{2} \mathrm{O}_{5}$. Charge-compensating $\mathrm{Ca}^{2+}$ ions were added to the melt in form of $\mathrm{CaCO}_{3}$.

The starting composition of the melt was: $\mathrm{Gd}_{3.05-x} \mathrm{Ga}_{4.95-x} \mathrm{Ca}_{\mathrm{x}} \mathrm{V}_{\mathrm{x}} \mathrm{O}_{12}$ with $\mathrm{x}=0.02475$ corresponding to a nominal vanadium composition of $0.5 \% \mathrm{~mol}$. The final concentration of vanadium in the crystal has not been determined.

The absorption spectra were recorded with use of a Cary 2300 spectrophotometer. The luminescence spectra, excited by the $514.5 \mathrm{~nm}$ argon-ion laser line have been measured in the set-up with a GDM-1000 monochromator equipped with an EMI 9684B S1-type sensitive cathode nitrogen-cooled photomultiplier and a Stanford Research model RS530 lock-in amplifier. The luminescence excitation and photoconductivity spectra were obtained with a $450 \mathrm{~W}$ Xenon lamp and a Jobin Yvon H10D monochromator. The photoconductivity spectra were measured using the blocking electrodes method. The luminescence decay kinetics of total $\mathrm{V}^{4+}$ luminescence were collected by exciting the samples with a pulsed YAG:Nd Quantel laser, using anti-Stokes line from a Raman shifter excited by a second-harmonic laser line and a RCA C31034 cooled photomultiplier equipped with a proper set of filters to cut off the excitation light. The kinetics were stored in a model $9400 \mathrm{~A}$ LeCroy digital oscil- 
loscope and analyzed by a computer. All spectra have been corrected for the equipment spectral sensitivity, efficiency of excitation and the penetration depth of the exciting light. The samples were placed in various cryostats to perform temperature measurements.

\section{Experimental results and discussion}

The temperature dependence of the GGG:VA+ crystal luminescence spectra are presented in the Fig.1. The observed luminescence has been assigned to the ${ }^{2} \mathrm{E}_{\mathrm{g}} \rightarrow{ }^{2} \mathrm{~T}_{2 \mathrm{~g}}$ transition in the $\mathrm{V}^{4+}$ octahedral centers only. No luminescence from tetrahedral $\mathrm{V}^{4+}$ centers has been detected in spite of effort and the use of the state-of-art equipment. The spectra can be deconvoluted into at least four Gaussian components, which are related to the splitting of the excited level by both the tetragonal field arising from a nearby charge-compensating ion and, most probably, the Jahn-Teller effect, known to strongly affect the $d^{1}$ - type spectra (2). The thermal population of these levels change the shape of the measured spectra. Strong thermal quenching of the luminescence can be observed, which diminishes the efficiency of the luminescence above $50 \mathrm{~K}$.

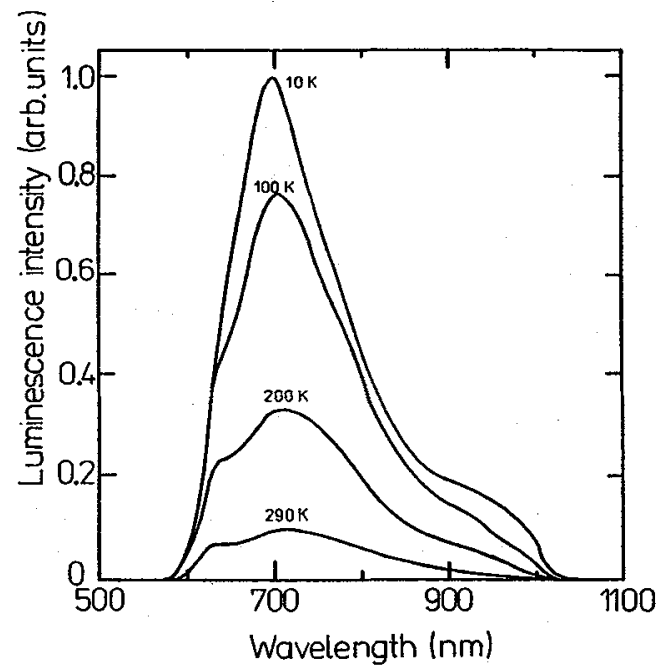

Fig.1.: The luminescence spectra of GGG: $\left(V^{4+}, \mathrm{Ca}^{2+}\right)$ crystal at various temperatures, excited by a $514.5 \mathrm{~nm}$ argon-ion laser line.

The absorption, luminescence excitation and luminescence spectra taken at $T=10 \mathrm{~K}$ in the region between $400 \mathrm{~nm}$ to $1100 \mathrm{~nm}$ are presented in Fig.2. The two bands in the absorption spectrum peaking at $448 \mathrm{~nm}$ and 513 are associated with the $\mathrm{V}^{4+}$ ions in the octahedral sites. These bands are also observed in the luminescence excitation spectrum, which proves that the observed luminescence is related to intrashell transitions of the $V^{4+}$ ions in octahedral sites. The two strong bands in the absorption spectrum, peaked at 753 $\mathrm{nm}$ and $822 \mathrm{~nm}$ have been assigned to the $\mathrm{V}^{4+}$ ions in tetrahedral sites (1).

Fig. 2 shows that the luminescence spectrum of the vanadium ions in the octahedral sites overlaps almost completely with the absorption spectrum of vanadium ions in the tetrahedral sites. This overlap establishes a very good condition for resonant energy transfer between these two types of sites. This process can be very important since purely nonradiative deexcitation of the vanadium ions in tetrahedral sites results in a very efficient quenching of the luminescence of the $\mathrm{V}^{4+}$ ions in octahedral sites. Although quantitative studies of such a process cannot be done without knowing the exact concentrations of vanadium ions at least in the tetrahedral sites (3), which act as energy acceptors, it is possible to estimate some limits of energy transfer parameters from the Forster-Dexter theory (3), if we assume the dipole-dipole interaction mechanism between 
the interacting ions. The estimated minimal value of the critical distance $\mathrm{R}_{\mathrm{O}}$ (the energy transfer probability is equal to radiative emission probability if the interacting ions are separated by the critical distance $R_{0}$ ) is equal to $11 \AA$, approximately.

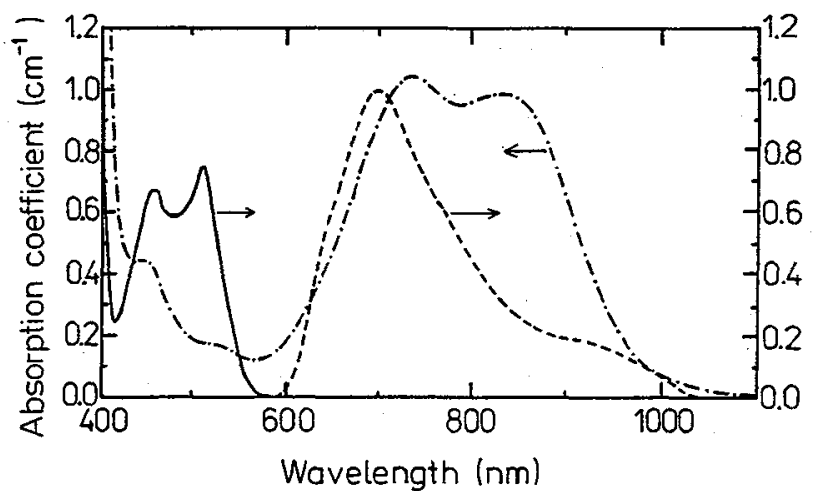

Fig. 2.: The luminescence (---), absorption (---) and luminescence excitation spectra ( $(-)$ of GGG: $\left(V^{4+}, \mathrm{Ca}^{2+}\right)$ crystal at $\mathrm{T}=10 \mathrm{~K}$ in the region of the intrashell transitions.

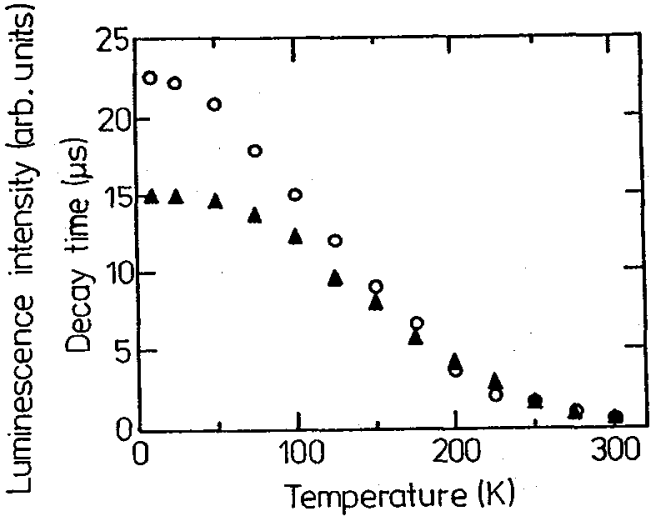

Fig.3.: The decay times of the $\mathrm{V}^{4+}$ luminescence calculated from the semi-exponential tail of the decay kinetics (M) and obtained from the computer fits of the Inokuti-Hirayama theory (000).

The luminescence decay kinetics were nonexponential at all temperatures in the range of $10 \mathrm{~K}$ to $300 \mathrm{~K}$. According to the Inokuti-Hirayama theory (4), assuming the dipole-dipole type of interaction, the luminescence decay kinetics $I(t)$ are expressed by the formula:

$$
I(t)=I_{0} \exp \left[-(t / s)-\sqrt{\pi} c / C_{0} \sqrt{(t / s)}\right]
$$

where $s$ is the decay time of the energy donor luminescence, $\mathrm{C}$ is the concentration of energy acceptors and $C_{0}$ is the critical concentration equal to: $C_{0}=3 /\left(4 \pi R_{0}{ }^{3}\right)$. The computer fits of this formula to the experimental kinetics, where the and $\mathrm{C} / \mathrm{C}_{0}$ values were treated as adjustable parameters, yield the temperature dependence of the luminescence decay times of the $\mathrm{V}^{4+}$ ions. This dependence is presented in Fig. 3. The temperature dependence of the decay times calculated from the semi-exponential tails of the experimental decay kinetics is also shown in Fig. 3 for comparison. Both values agree well at higher temperatures, but at low temperatures (below $150 \mathrm{~K}$ ) the decay times obtained from the computer fits are reasonably longer than the ones calculated from the tails of the decay kinetics. The true values of the decay times should not be shorter than the latter ones. Therefore we conclude that strong energy transfer from the $\mathrm{V}^{4+}$ ions in octahedral sites to those in tetrahedral sites occurs in the GGG: $\mathrm{V}^{4+}$ crystals. The real values of the decay times can be measured only in very diluted samples, where the energy transfer processes are minimized due to large inter-ionic distances. The strong thermal quenching of the luminescence, which begins at relatively low temperatures and decreases the luminescence decay time below $1 \mu \mathrm{s}$ at room temperature (in agreement with the temperature dependence of the relative luminescence intensity) is documented in Fig. 3. 


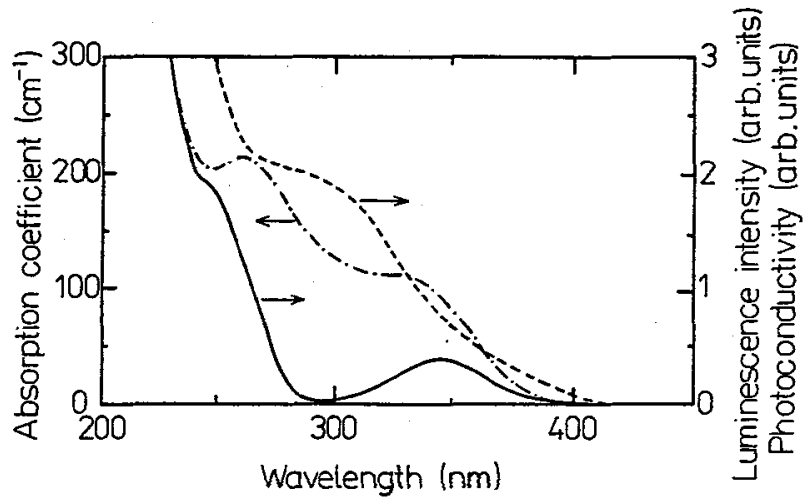

Fig.4.: The absorption (---.) and photoconductivity spectra $(--)$ of thin GGG: $\left(\mathrm{V}^{4+}, \mathrm{Ca}^{2+}\right)$ crystal, the $\mathrm{V}^{4+}$ luminescence excitation spectrum $(-)$ at $\mathrm{T}=10 \mathrm{~K}$ in the region $200 \mathrm{~nm}-$ $400 \mathrm{~nm}$.

Very strong bands are observed in the absorption spectra of thin GGG:V4+ samples and the luminescence excitation spectra of octahedral $\mathrm{V}^{4+}$ ions in the ultraviolet region (see Fig.4). They are much stronger than the bands associated with the $\mathrm{v}^{4+}$ internal transitions. These bands occur at the same spectral position in both types of spectra. The intensity of the bands in the luminescence excitation measurements is strongly temperature deactivated. Additionally, the photoconductivity spectra show that the onset of photoconductivity, which occurs at $400 \mathrm{~nm}$, approx., agrees well with the onset of the bands. The origin of the bands is most probably associated with the electron from $\mathrm{Ca}^{2+}$ chargecompensating ions self-trapped on the $\mathrm{V}^{4+}$ ions, positively charged relatively to the GGG lattice. The so-called small polarons (5) are formed in this way. The small polarons, strongly interacting with the lattice, give rise to characteristic, very broad bands in the absorption spectra and to a weak conductivity due to their hopping motion in the lattice. Charge-transfer transition can also be present in this spectral region.

\section{Conclusions}

The results of the optical investigations of the GGG:V4+ crystals show that in this material there is a very efficient excitation mechanism of the dopant luminescence, which is related to the formation of small polarons in the crystals. The crystal exhibits serious drawback as a laser material due to the presence of $\mathrm{V}^{4+}$ ions in the tetrahedral sites, which efficiently quenches the luminescence from the $\mathrm{V}^{4+}$ ions in the octahedral sites, and additionally to the strong thermal quenching, which occurs at relatively low temperature.

\section{References:}

1. A. Brenier, C. Madej, C. Pedrini, G. Boulon, Chem. Phys. Lett. 177,590 (1991).

2. R.M. Macfarlane, J.Y. Wong, M.D. Sturge, Phys. Rev. 166, 250 (1968).

3. D.L. Dexter, J. Chem. Phys. 21, 836 (1953), Phys. Rev. 126, 1962 (1962).

4. M. Inokuti, F. Hirayama, J. Chem. Phys. 43, 1978 (1965).

5. O.F. Schirmer, Z. Physik B 24, 235 (1976) 